\title{
Theoretical and Experimental Investigation on Performance Improvement of Solar Hot Water System Under Real Weather Conditions at Ho Chi Minh City, Vietnam
}

\author{
Le Minh Nhut \\ Department of Thermal Engineering, Faculty of Vehicle and Energy Engineering, Ho Chi Minh City University of Technology and \\ Education, Ho Chi Minh, Vietnam \\ Email address: \\ nhutlm@hcmute.edu.vn \\ To cite this article: \\ Le Minh Nhut. Theoretical and Experimental Investigation on Performance Improvement of Solar Hot Water System Under Real Weather \\ Conditions at Ho Chi Minh City, Vietnam. American Journal of Engineering and Technology Management. Vol. 3, No. 1, 2018, pp. $29-34$. \\ doi: 10.11648/j.ajetm.20180301.13
}

Received: February 25, 2018; Accepted: March 11, 2018; Published: April 2, 2018

\begin{abstract}
This paper presents the results of theoretical and experimental investigation to determine the optimal flow rate of collector loop to improve the performance of a solar hot water system under real weather conditions at Ho Chi Minh City, Vietnam. The optimal flow rate of flat-plate collector loop is researched based on the relationship between the useful heat gain of the flat plate collectors and the electricity consumption of the collector pump. The result of the simulation and experiment shows that the optimal flow rate was determined at the value of $0.132(\mathrm{~kg} / \mathrm{s})$. Besides, the effects of various parameters such as initial water temperature of storage tank, flat plate collector area and volume of storage tank are investigated. Furthermore, the validation of simulation and experiment results of the progress of the water temperature in the storage tank is also evaluated.
\end{abstract}

Keywords: Flat-Plate Collectors, Optimal Flow Rate, Collector Loop, Useful Heat Gain, Electricity Consumption

\section{Introduction}

The world is facing many problems such as population growth, environmental pollution, greenhouse effect, energy crisis. In particular, the issue that is considered the hottest is the energy crisis. This is due to the rapid economic development as well as the significant increase in the world's population in recent years. Therefore, the research on renewable energy technology has become a hot topic in recent years. Especially, research on solar energy has concentrated on solar thermal systems for space heating, cooling, and water heating; most of the attention has been focused on solar domestic hot water systems, which have been well developed in many countries for many years.

In 2008, Badescu [1] evaluated the performances of a solar collector system by optimal control flow strategies for a closed loop flat plate solar collector. The optimal operation strategy includes two step up and down jumps of the fluid flow rate in the collector loop was investigated. The results show that the solar collector efficiency is higher for the optimal control strategy than for the constant mass flow rate strategy. Salteil and Sokolov [2] presented a numerical analysis of the optimal flow rate for a multicomponent solar collector with two types of configurations: recirculating and once-through. The weather conditions were assumed as a sinusoidal function of time. Zhiyong et al. [3] presented the heat transfer model of all-glass vacuum tube collector used in forced-circulation solar water heating system. In this study, the simplified heat transfer of collector is composed of the natural convection in single glass tube and forced flow in manifold header. Thus the heat balance equation of water in single tube and the heat balance equation of water in manifold header have been established. The flow equation is also built by analyzing the friction and buoyancy in tube. Jordan and Vajen [4] presented the influence of the domestic hot water load profiles on the fractional energy saving of a solar combisystem. The analysis results show that, the highest values of the electric energy demand of pumps for draw-offs is in the early afternoon while the differences of the electric energy demand of pumps for morning and noon profiles differ by about $1 \%$-point. An experimental study on the effect of discharge from different levels in solar storage tanks on the thermal performance for both the small solar 
domestic hot water (SDHW) system and solar combisystem was reported by Furbo et al. [5]. Person and Rönnelid [6] developed a solar heating system to improve solar gains by using hot water to heat dishwashers and washing machines. Kovarik and Lesse [7] carried out a theoretical study on the problem of optimal control flow rate in order to maximize the difference between useful heat gain and the energy consumption of a solar pump. In their study, a flat plate collector and a storage tank were analyzed with the assumption that there is no domestic hot water load supply to the user during pumping. The collected solar energy was directly supplied into the thermal storage tank without the collector loop heat exchanger. Orbach et al. [8] worked on the optimal control of a solar collector loop. They presented both bilinear distributed parameter model for the collector loop temperature and bilinear lumped parameter model for the storage fluid temperatue. Loomans and Visser [9] pointed out the application of the genetic algorithm in a design support tool to optimize the design parameters of solar hot water systems such as the collector areas, the thermal storage tank volumes, and the collector heat exchanger area and so on. Pichler et al. [10] proposed a linear predictive control approach for auxiliary energy supply to improve collected solar energy and minimize auxiliary heat demand of the solar assisted heating systems for a single-family house. From the numerical results the authors concluded that the auxiliary energy demand can be reduced up to $40 \%$ while the maximum increasing of the monthly solar fractions is $5 \%$. Nhut and Park [11] proposed a new function to determine the water flow through loop of collector based on the difference between the water temperature at solar collector outlet and the water temperature in the storage tank and these simulations have been performed under South Korean latitudes and climate during a single spring day. Sanda and Badescu [12] presented an analysis of the optimal operation of the systems with flat solar collectors in closed circuit, to convert the solar energy in thermal energy - hot water (DHW - domestic hot water), by comparing the various models from the literature to improve the performance of thermal solar collectors.

This paper presents results on the analysis of the thermal performance of a solar flat-plate collectors domestic hot water system under real weather conditions at Ho Chi Minh City of Vietnam to obtain an optimal mass flow rate in collectors loop based on the relationship between the useful heat gain of solar collector and the electricity consumption of solar pump to improve its thermal performance. The experimental investigation is conducted to confirm the validity of value of mass flow rate.

\section{System Description}

The solar domestic hot water system is designed for installation on the front of central building at the Ho Chi Minh City University of Technology and Education in Vietnam. A schematic diagram of the system is shown in Figure 1. It consists of four flat plate collectors which were connected in parallels and has the total collection surface areas of $8 \mathrm{~m}^{2}$, the vertical type thermal storage tank has 300
L capacity and is constructed of stainless steel with polyurethane insulation. The water flow rate through collector loop is experimented in range of $4.8(1 / \mathrm{m})$ to 9.6 (l/m) (Duffie and Beckman [13]).
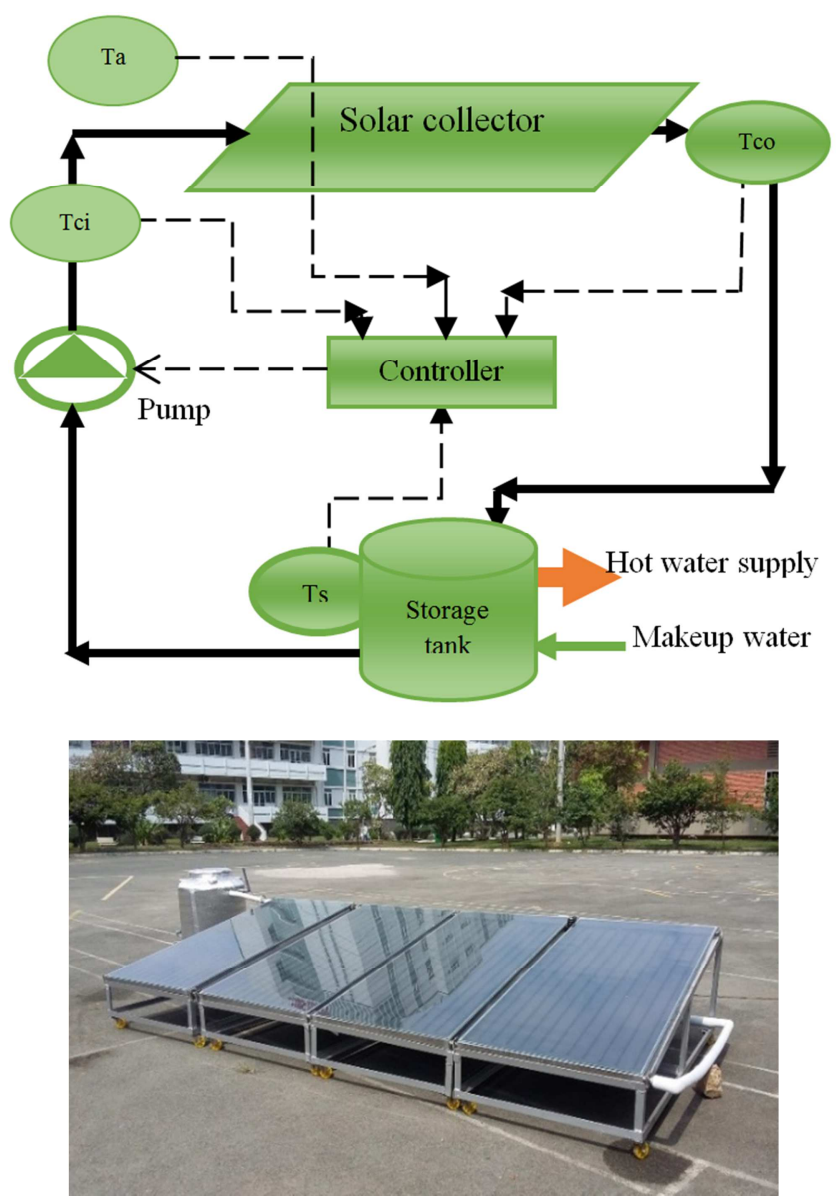

Figure 1. Schematic diagram of the solar flat-plate collector domestic hot water system with the constant flow rate in collectors loop.

The operation of the system can be described as follows. For the collector loop, when the difference between the outlet temperature of the collector and the bottom water temperature of the storage tank is higher than the set value of $\Delta T_{o n}$, the collector pump is switched on, and will be switched off if this value is lower than the value of $\Delta T_{\text {off }}$. When the collector pump is switched on, solar energy is transferred from the solar collector to the storage tank through the heat exchanger in the collector loop.

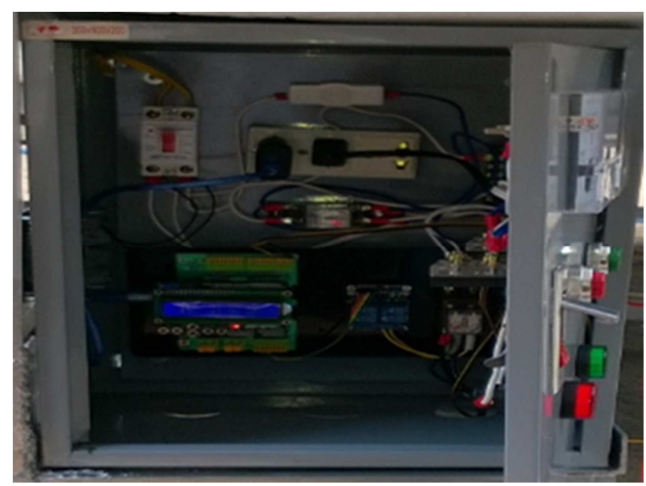




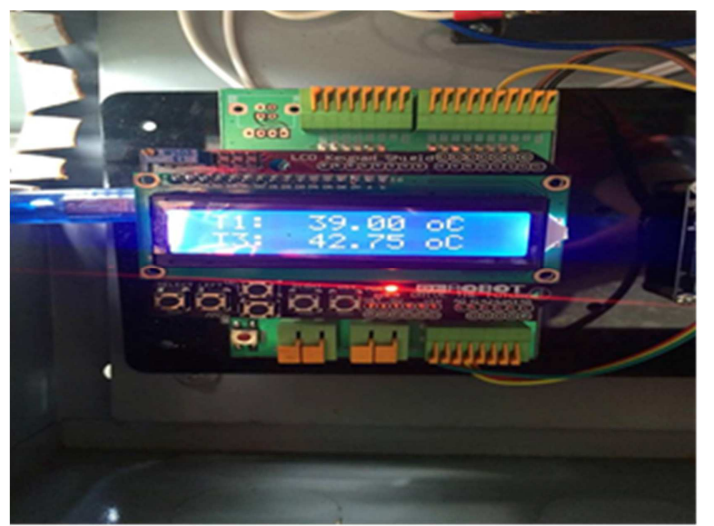

Figure 2. Schematic diagram of the controller for the collectors loop.

\section{The Mathematical Model}

The useful heat gain $\mathrm{Q}_{\mathrm{u}}$ of the solar collector is taken from the calculation by Duffie and Beckman [13] as follows:

$$
Q_{u}=A_{c} \cdot F_{R}\left[(\alpha \tau) \cdot I_{t}-U_{L}\left(T_{c i}-T_{a}\right)\right]=m c_{p}\left(T_{c o}-T_{c i}\right)
$$

Where $T_{\text {co }}$ and $T_{c i}$ are the outlet and inlet temperature of collectors, $\mathrm{T}_{\mathrm{a}}$ is ambient temperature, $\mathrm{U}_{\mathrm{L}}$ and $\mathrm{A}_{\mathrm{c}}$ are collector overall heat loss coefficient and collector area, $\tau \alpha$ and $\mathrm{I}_{\mathrm{t}}$ are cover transmittance absorptance and solar radiation, $m$ and $c_{p}$ are mass flow rate and water specific heat coefficient, $F_{R}$ is the collector heat removal factor, which is related to the collector area, overall heat loss coefficient, and mass flow rate and is determined as:

$$
F_{R}=\frac{m c_{p}}{A_{c} U_{L}}\left[1-\exp \left(-\frac{A_{c} U_{L} F^{\prime}}{m c_{p}}\right)\right]
$$

Where is the collector efficiency factor, given by:

$$
F^{\prime}=\frac{\frac{1}{U_{L}}}{W\left[\frac{1}{U_{L}[D+(W-D) F]}+\frac{1}{C_{b}}+\frac{1}{\pi D_{i} h_{f, i}}\right]}
$$

The electricity consumption of the collector pump is calculated as provided by Saltiel and Sokolov [2] and Badescu [1] as follows:

$$
\mathrm{E}_{\mathrm{p}}=\mathrm{K}_{\mathrm{p}} \mathrm{m}^{3}
$$

An energy balance on the unstratified water storage tank is expresses as:

$$
T_{s-n}=T_{s}+\frac{\Delta t}{\left(M C_{p}\right)_{s}}\left[Q_{u}-Q_{w}-\left[\left(U_{s} A_{s}\right)\left(T_{s}-T_{a}\right)\right]\right]
$$

Where $C_{t}=M \cdot c_{p}$ is the heat capacity of the water in the storage tank, $\mathrm{T}_{\mathrm{s}}$ is hot water temperature in storage tank and the heat loss of storage tank is given by:

$$
Q_{s t}=U_{s} A_{s}\left(T_{s}-T_{a}\right)
$$

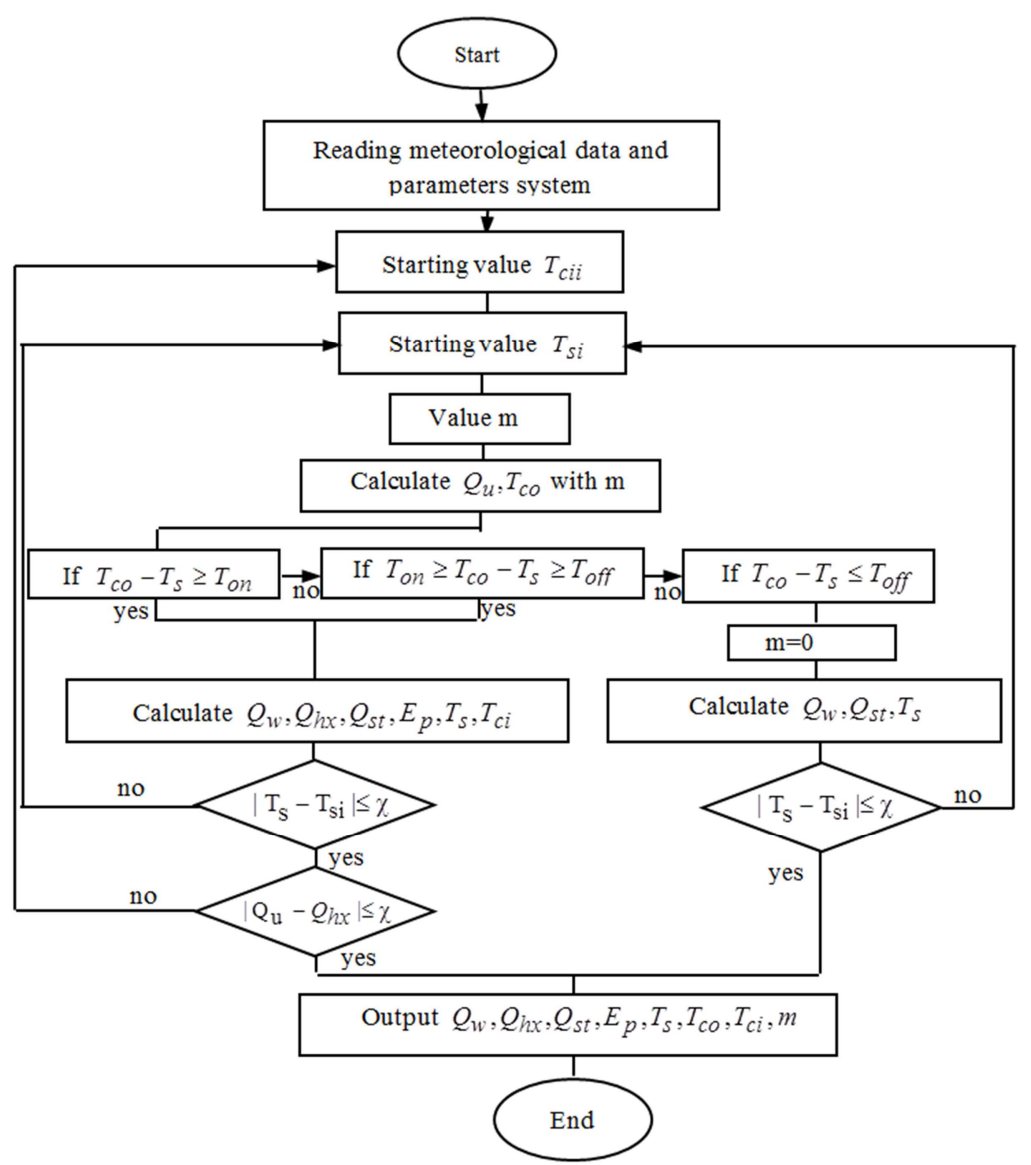

Figure 3. Flow chart of the proposed program for calculating of constant mass flow rate in collector loop. 
Where $A_{s}, U_{s}$ are the surface area of storage tank and the heat transfer coefficient between the water in the tank and environment air where storage tank is locates. Heat transfer coefficient between the water in the tank and environment air is $U_{s}=0.33 \mathrm{~W} /\left(\mathrm{m}^{2} K\right)$ [10]. The heat flux $Q_{w}$ delivered from storage tank to the user is expressed as:

$$
Q_{w}=m_{w} c_{p}\left(T_{s}-T_{w i}\right)\left[1-\exp \left(-\frac{U_{w} A_{w}}{m_{w} c_{p}}\right)\right]
$$

The values of the make up mass flow rate $m_{w}$ and make up water temperature $T_{w i}$ are given by input data.

In this study, A MATLAB program with above derived mathematical model developed to simulate optimal performance of the collector loop, the values of mass flow rate for simulation in range of $4.8(1 / \mathrm{m})$ to $9.6(1 / \mathrm{m})$ (Duffie and Beckman [13]). The flow chart of the calculation program is shown in Figure 3.

\section{Results and Discussion}

In this case research, the real weather condition of Ho Chi Minh city on ten clear days of June, 2016 were taken into account to determine the optimal flow rate in the flat plate collectors loop based on the the useful heat gain $\mathrm{Q}_{\mathrm{u}}$ and electricity consumption of collector pump $E_{p}$. The optimal flow rate is determined based on the proposing by Saltiel and Sokolov [2], it mean that the useful heat gain is maximized when the best flow rate would be at the point where the distance between the useful solar heat gain and the electricity consumption of the collector pump curve is the highest.

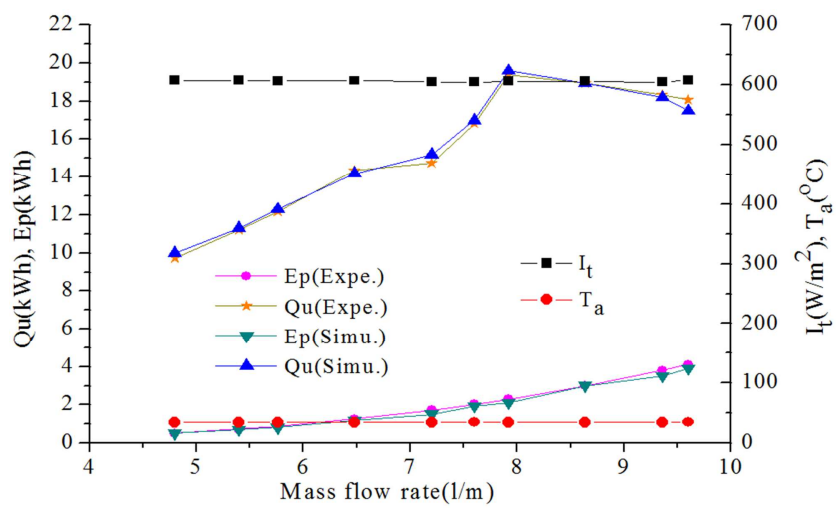

Figure 4. Effect of mass flow rate in collectors loop on the useful heat gain $Q_{u}$ and electricity consumption of collector pump $E_{p}$ of collector pump during the day.

Figure 4 shows the effect of the mass flow rate on the useful heat gain $\mathrm{Q}_{\mathrm{u}}$ and electricity consumption of collector pump $\mathrm{E}_{\mathrm{p}}$ of collector pump, in this results, the value of the useful heat gain $\mathrm{Q}_{\mathrm{u}}$ and electricity consumption of collector pump $\mathrm{E}_{\mathrm{p}}$ of collector pump are the total of an experimental day, while the solar radiation $\mathrm{I}_{\mathrm{t}}$ and ambient temperature $\mathrm{T}_{\mathrm{a}}$ are the average values of an experimental day. As indicated in Figure 4, when the mass flow rate through collector loop in range of $4.8(1 / \mathrm{m})$ to $9.6(1 / \mathrm{m})$, the amount of useful heat gain $\mathrm{Q}_{\mathrm{u}}$ increased from $9.72(\mathrm{kWh})$ to $19.4(\mathrm{kWh})$ and then gradually decreased to $18.05(\mathrm{kWh})$, while the amount of electricity consumption of collector pump $\mathrm{E}_{\mathrm{p}}$ gradually increased from $0.51(\mathrm{kWh})$ to 2.3 $(\mathrm{kWh})$ and then rapidly increased to $4.1(\mathrm{kWh})$. As the proposing by Saltiel and Sokolov [2], the optimal flow rate is determined at the value of $7.92(1 / \mathrm{m})$ because at this point the distance between the useful solar heat gain and the electricity consumption of the collector pump curve is the highest. Besides, Figure 4 also shows the validity results between the simulation and experiment of the useful solar heat gain and the electricity consumption of the collector pump, the error between simulation and experiment just is $1 \%$, this is demonstrated that the value of optimal flow rate of $7.92(1 / \mathrm{m})$ is completely reliable. The values of mass flow rate of 7.92 $(1 / \mathrm{m})$ obtained from the above results will be used to calculate in all of the following cases.
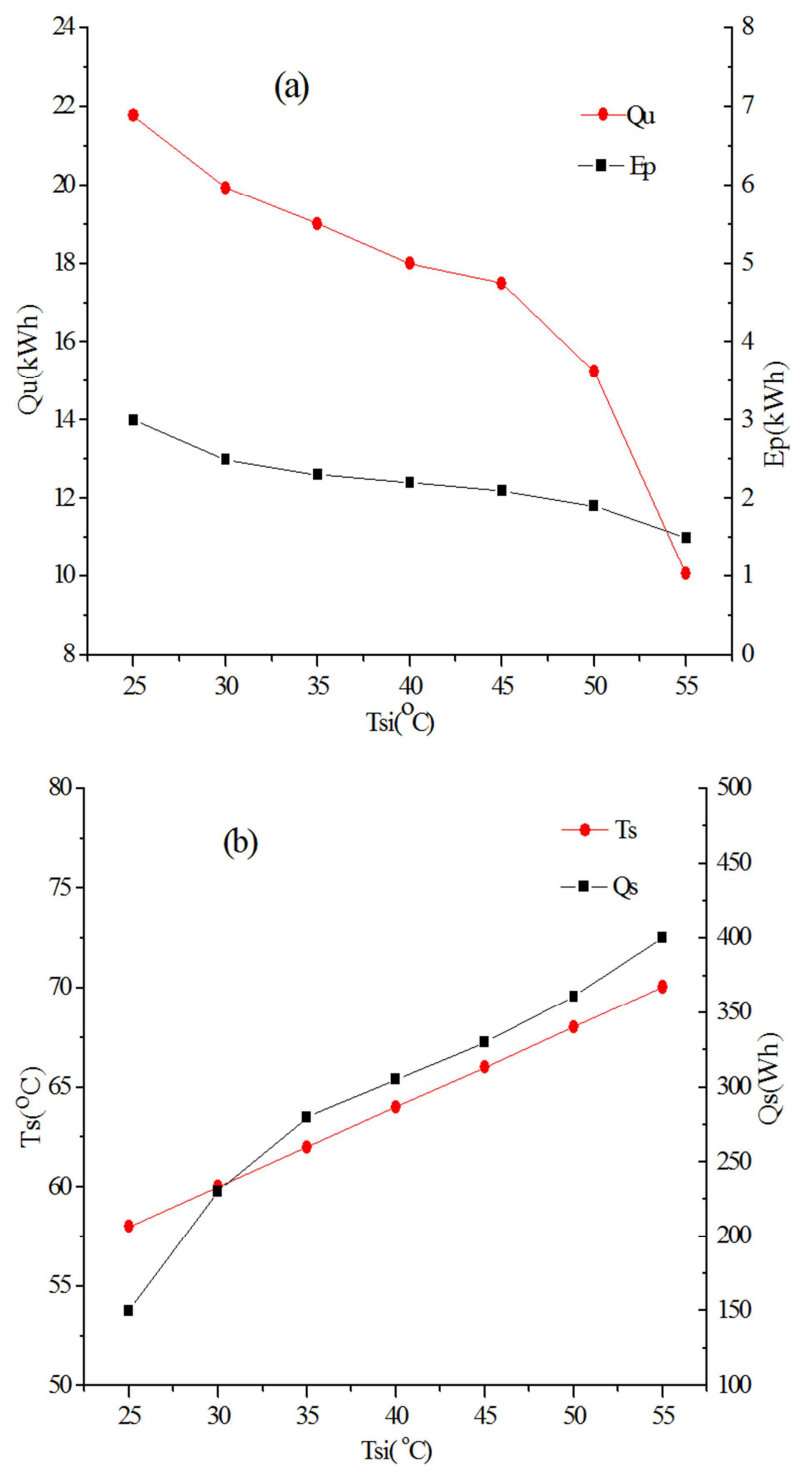

Figure 5. Effect of initial water temperature $T_{s i}$ of storage tank on the useful heat gain $Q_{u}$ and electricity consumption $E_{p}$ of collector pump, heat loss $Q_{s}$ and water temperature $T_{s}$ at the end of storage tank during the experimental fair days (July, 2016). 
As shows in Figure 5 (a), the effect of initial water temperature $\mathrm{T}_{\mathrm{si}}$ of storage tank on the useful heat gain $\mathrm{Q}_{\mathrm{u}}$ and electricity consumption $E_{p}$ of collector pump, when the initial water temperature in the storage tank was experimented in the range of $25^{\circ} \mathrm{C}$ to $55^{\circ} \mathrm{C}$, the useful heat gain $\mathrm{Q}_{\mathrm{u}}$ decreases from $21.7(\mathrm{kWh})$ to $10.05(\mathrm{kWh})$, and the electricity consumption $\mathrm{E}_{\mathrm{p}}$ decreases from $3(\mathrm{kWh})$ to $1.5(\mathrm{kWh})$, this is due to the increase in initial water temperature $\mathrm{T}_{\mathrm{si}}$ leads to the operation time of collectors pump is decreased because the difference between the outlet temperature of the flat plate collectors and the bottom water temperature of the storage tank is quickly reduced. Figure 5 (b) shows that the increase in the initial water temperature $T_{\mathrm{si}}$ leads to the rapid increase of heat loss $\mathrm{Q}_{\mathrm{s}}$ and water temperature $\mathrm{T}_{\mathrm{s}}$ of storage tank. This is explained that the increase of $\mathrm{T}_{\mathrm{si}}$ leads to the increase of the difference between the water temperature $T_{\mathrm{s}}$ in storage and environment temperature $\mathrm{T}_{\mathrm{a}}$.

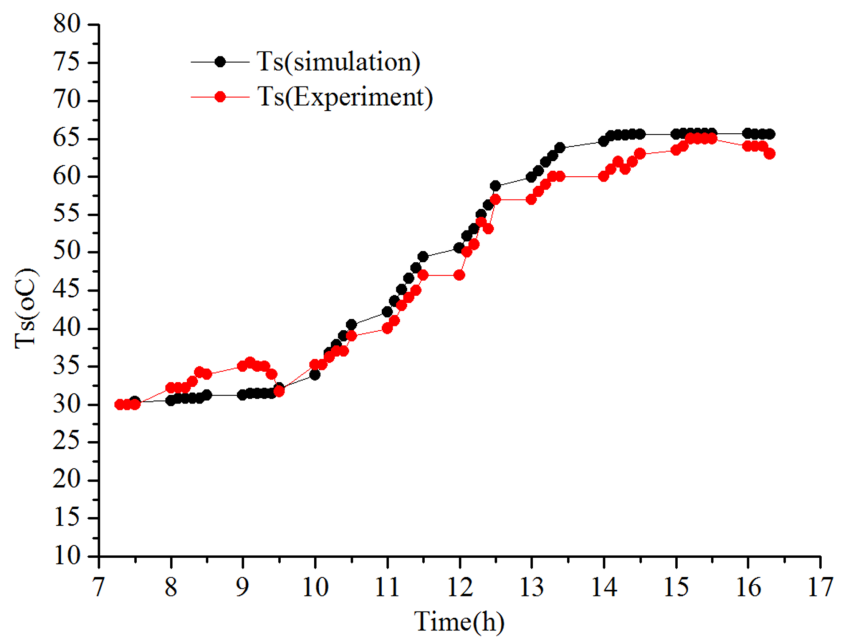

Figure 6. Variation of water temperature of storage tank vs. time during the day.

Figure. 6 shows the variation of water temperature of the storage tank versus time, the water temperature of the storage tank gradually increased and reaches to $63^{\circ} \mathrm{C}$ at the end of an experiment fair day. It is due to the change of the ambient temperature and solar radiation. Agreement between simulated and measured data is good with comparative water temperature of the storage tank being within $2^{\circ} \mathrm{C}$. This lends confidence in the validity between measured and simulated results.

As seen in Figure 7 (a), when the flat-plate collectors area $A_{c}$ ranges from $4 \mathrm{~m}^{2}$ to $12 \mathrm{~m}^{2}$, both the the useful heat gain $\mathrm{Q}_{\mathrm{u}}$ and electricity consumption $E_{p}$ of collector pump are quickly increased, this is due to the rapid increase of the outlet temperature $\mathrm{T}_{\mathrm{co}}$ of flat-plate collectors. As indicated in Figure 7 (b), when the flat-plate collectors area $A_{c}$ rises, both the heat loss $\mathrm{Q}_{\mathrm{s}}$ and the water temperature $\mathrm{T}_{\mathrm{s}}$ of storage tank also rapidly increased. This can be explained that the increase of collector area leads to the significant increase of the the useful heat gain $\mathrm{Q}_{\mathrm{u}}$ and the difference between the water temperature in the storage tank $T_{s}$ and ambient temperature $\mathrm{T}_{\mathrm{a}}$. However, the increase area in the collector area leads to the investment cost of the solar hot water system will be increased.
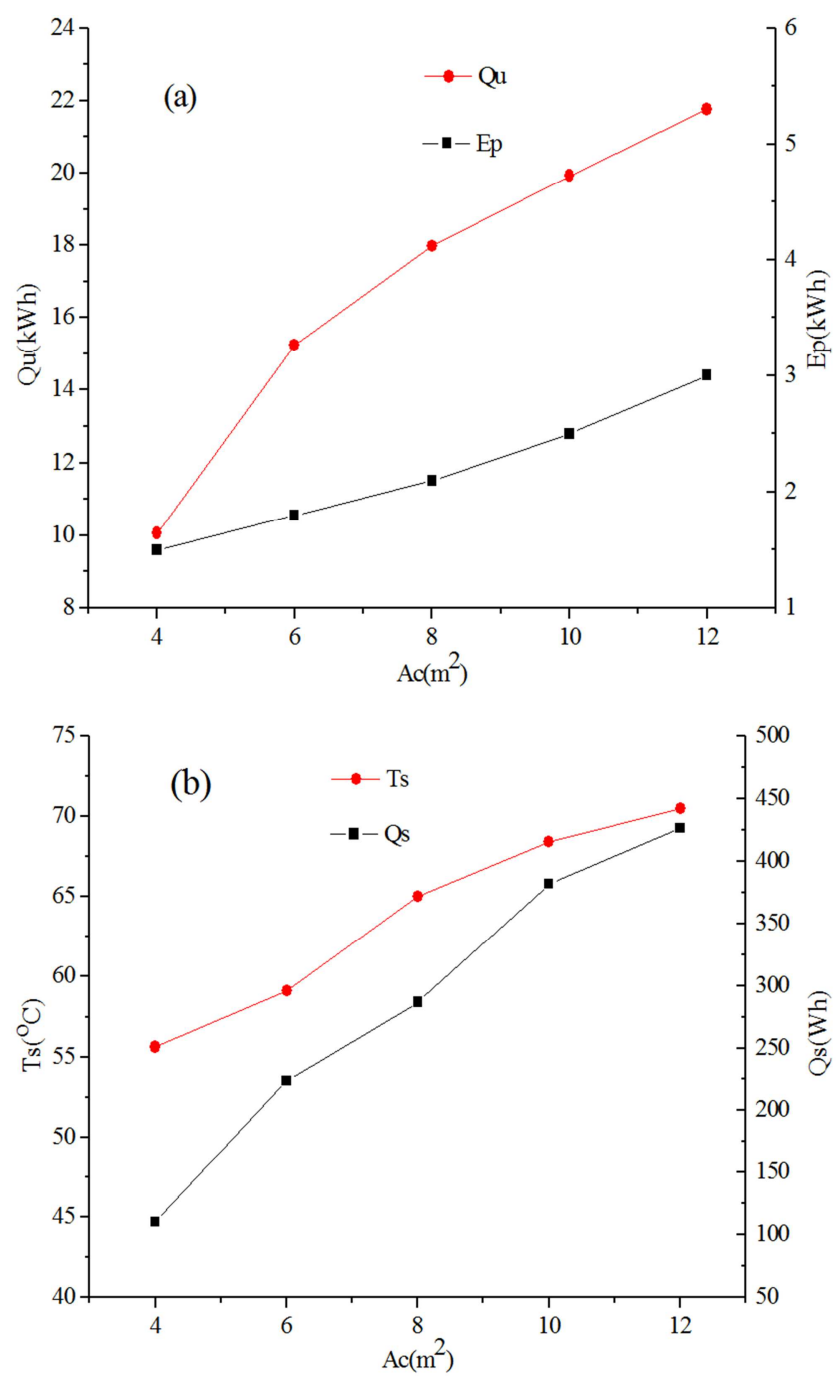

Figure 7. Effect of collector area $A_{c}$ on the useful heat gain $Q_{u}$ and electricity consumption $E_{p}$ of collector pump, heat loss $Q_{s}$ and water temperature $T_{s}$ at the end of the day (July, 2016).

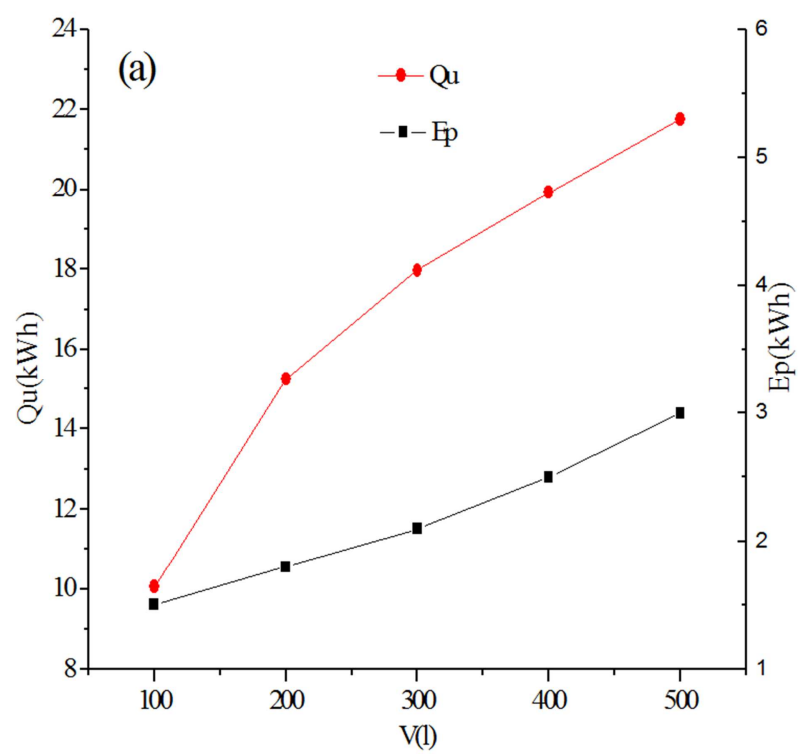




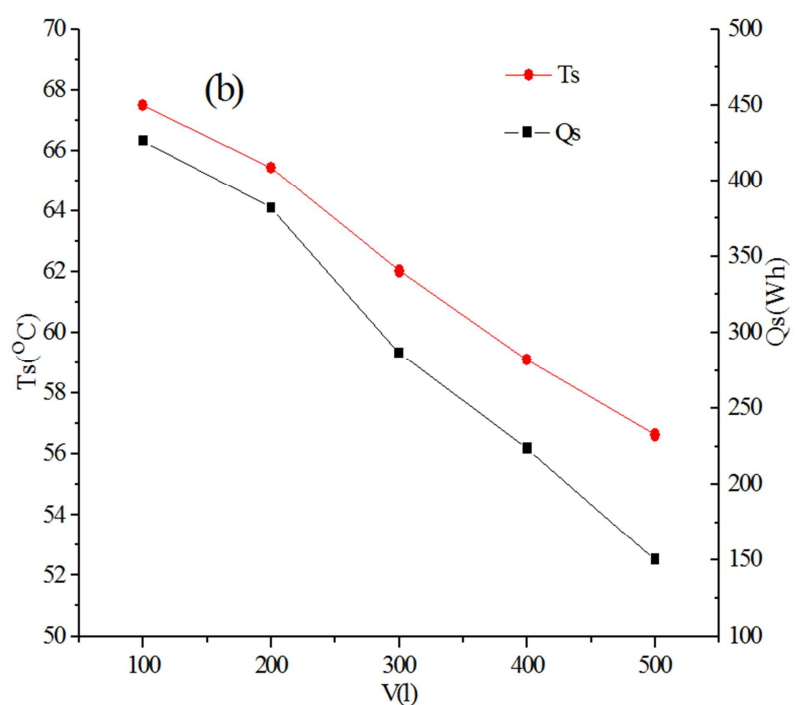

Figure 8. Effect of volume of storage tank on the useful heat gain $Q_{u}$ and electricity consumption $E_{p}$ of collector pump, heat loss $Q_{s}$ and water temperature $T_{s}$ at the end of the day (July, 2016).

Figure 8 (a) shows that the increase in the volume of storage tank causes a rapid increase of the useful heat gain $\mathrm{Q}_{\mathrm{u}}$ and electricity consumption $\mathrm{E}_{\mathrm{p}}$ of collector pump, this is due to the difference between the outlet temperature of flat-plate collectors strongly increased. As indicated in Figure 8 (b), when the volume of storage tank in ranges from 100 (litre) to 500 (litre), the difference between the water temperature $T_{s}$ of storage tank and ambient temperature $T_{a}$ is decreased, this leads to the heat loss Qs of storage tank also reduced. However, the reducing of storage tank is limited by the required temperature by the user.

\section{Conclusions}

This paper proposes a constant mass flow strategy for a collector loop, a Matlab programs is written and developed based on a simplified mathematical model to determine the optimal flow rate of collector of solar hot water system under real weather conditions at Ho Chi Minh City, Vietnam. The optimal flow rate is obtained at the value of $0.132(\mathrm{~kg} / \mathrm{s})$ $(7.92(1 / \mathrm{m}))$ and is recommended for using in the flat plate collector loop of the solar hot water system in weather conditions of South Vietnam. Besides, the study results also show that the thermal performance is strongly affects by the various parameters such as initial water temperature of storage tank, flat plate collector area and volume of storage tank.

\section{Acknowledgements}

This work was supported by research grant of the Ho Chi Minh City University of Technology and Education, Vietnam (Project No. T2017-30TĐ).

\section{References}

[1] Badescu, V., Optimal control of flow in solar collector systems with fully mixed water storage tanks. Energy Conversion and Management 49, 169-184, 2008.

[2] Saltiel, C., Sokolov, M., Optimal control of a multicomponent solar collector system. Solar Energy 34, 463-473, 1985.

[3] Zhiyong, L., Chao, C., et al., All-glass vacuum tube collector heat transfer model used in forced-circulation solar water heating system. Solar Energy 84, 1413-1421, 2010.

[4] Jordan, U., Vajen, K. Y., Influence of the DHW load profile on the fractional energy saving: A casevstudy of a solar combisystem with TRNSYS simulation. Solar Energy 69, 197-208, 2000 .

[5] Furbo, S., Andersen, E., et al., Performance improvement by discharge from different levels in solar storage tanks. Solar Energy 79, 431-439, 2005.

[6] Persson, T., Rönnelid, M., Increasing solar gains by using hot water to heat dishwashers and washing machines. Applied Thermal Engineering 27, 646-657, 2007.

[7] Kovarik, M., Lesse, P. F., Optimal control of flow in low temperature solar heat collector. Solar Energy 18, 431-435, 1976.

[8] Orbach, A., Rorres, C., et al., Optimal control of a solar collector loop using a distributed-lumped model. Automatica $17,535-539,1981$.

[9] Loomans, M., Visser, H., Application of the genetic algorithm for optimization of large solar hot water systems. Solar Energy 72, 427-439, 2002.

[10] Pichler, M. F., Lerch, W., et al., A novel linear predictive control approach for auxiliary energy supply to a solar thermal combistorage. Solar Energy 101, 203-219, 2014.

[11] Nhut, L. M., Park, Y. C. A Study on Automatic Optimal Operation of a Pump For Solar Domestic Hot Water System. Elsevier, Solar Energy 98, 448-457, 2013.

[12] Sanda, B., Badescu, V., Improving the Performance of Systems with Solar Water Collectors Used in Domestic Hot Water Production. Energy Procedia 112, 398-403, 2017.

[13] Duffie, J. A., Beckman, W. A., 2006. Solar Engineering of Thermal Processes, third ed. John Wiley \& Sons, New York. 